\title{
Using Qualitative Methods to Generate Data for
}

Instructional Development

\section{Donald H. Wulff and Jody D. Nyquist}

University of Washington

Instructional and faculty development consultants are continually searching for ways to provide instructors with valid information and insights about the quality of their teaching. This information should identify problems, provide baseline assessments against which instructional improvement can be measured, and make recommendations/suggestions for instructional improvement. As with any problem solving effort, the entire process must be based on verifiable, valid and reliable data.

Collecting such data is particularly difficult in teaching contexts for several reasons: 1 ) teaching environments are extremely complex; 2) effective teachers represent a wide range of idiosyncratic behaviors and styles; 3 ) the roles of students and student/teacher relationships vary from context to context; and 4) different courses require differences in course goals, daily objectives, and student outcomes. Analyzing what goes on in classrooms, therefore, requires a systematic approach including the specific research steps of data collection, data analysis and interpretation and application of findings. We have found that certain kinds of data are useful for such purposes and that qualitative research methods provide an effective way of collecting such data. 


\section{DEFINING QUALITATIVE METHODS}

Since its inception in educational research, qualitative methodology has been referred to in a variety of ways including qualitative research, case or field studies, naturalistic inquiry, participant observation studies, ethnographies, and interpretive research. Before we look at the kinds of data that qualitative methods can provide, then, it is useful to achieve some common understanding of what is meant by qualitative methods. Explanations by Philipsen (1982) and Patton (1980) have been especially helpful for providing insights about qualitative methodology as we use it for instructional development.

Philipsen (1982), in his discussion of the qualitative case study, suggests that qualitative inquiry is in situ, exploratory, openly-coded, and participatory. He explains these dimensions of qualitative inquiry in the following way: "The investigator searches the context in which the phenomenon of interest occurs naturally without deliberately producing the phenomenon; explores the phenomenon of interest by describing it without total reliance upon pre-determined codes or categories; and uses his or her own experiencing of the phenomenon as one source of insight into it" (Philipsen, 1982, p. 10). This explanation is useful for suggesting what qualitative inquiry entails.

The primary methods of collecting qualitative data are interviewing, observing, and studying printed materials. ${ }^{1}$ According to Patton (1980), the kind of information collected from a qualitative measurement process includes detailed descriptions, direct quotations, and excerpts or passages from written documents (p. 22). These kinds of data can be analyzed to provide insights into what is occurring in dynamic, multivariate classroom environments. ${ }^{2}$

\section{GENERATING USEFUL DATA}

The fact that the classroom environment is dynamic, individualistic and multivariate requires generation of data that can provide the most complete understanding of the instructional process. Unfortunately, the generation of such data is not an easy task. As Cooper (1982) suggests: "Gaining access to the internal workings of the process to uncover how the parts of the system are integrated and function is a challenge" (p. 2). We find, however, that we obtain a more holistic understanding of 
the instructional process for an individual instructor if we can generate data that meet the following criteria:

1. The data represent the complexity of classroom environments.

2. The data account for context variables.

3 . The data incorporate the perspectives of classroom participants whether they be teachers, students, visitors, and/or administrators.

4. The data represent the specific case.

We have found that data generated by qualitative methods allow us to meet these criteria successfully.

\section{Classroom Complexity}

Data generated by qualitative methods meet the first criterion by providing a way to capture the interactive complexity of the classroom environment. Numerous researchers contend that although traditional research approaches have been insightful in many ways, they should not be relied on as the only sources of data with which to study teaching effectiveness. Pedersen (1975) observes that the teaching-learning sequence contains variables that are so numerous and complex in their interaction with one another that the process is difficult to define and study: "The teacher's influence upon educational outcomes interacts with the influence of so many other agents that it becomes extremely difficult to determine with much certainty the effects of a particular teacher upon a particular pupil" (p. 18). The exploratory nature of qualitative methods, however, provides a way for the variables to emerge without the constraints of predetermined units and measurement categories. As Cooper (1982) suggests:

Classroom teaching is indeed complex and interactive. To get inside the instructional process, inquiry methods are needed which allow the consultant and instructor to examine parts while not losing sight of the whole; to explore the event from within while standing outside and looking in; to fix an event in time while remembering that in its context it is ongoing; to attend to various views of the same event; and to remain flexible and open to ideas. The fieldwork techniques of school ethnographies provide means to examine, analyze, and understand the interaction dynamics and the structure of classroom teaching. (p. 2) 


\section{Context}

Data generated by qualitative methods meet the second criterion by providing a way to address context variables in the study of the teaching-learning process. As McKenna (1981) points out:

Success in teaching, however defined and assessed, is highly contextual. Therefore, if evaluation of teaching and teachers is to serve meaningful and useful purposes, it must not only identify and define all the mitigating contexts but must also take into account their influences, both constructive and negative, in determining success. (p. 23)

The field methods of qualitative inquiry allow the investigator to study teaching and learning in the natural context and to account for contextual variables which influence the teaching process.

\section{Participant Perspectives}

Data generated by qualitative methods meet the third criterion by allowing for the incorporation of the perspectives of the participants. Numerous researchers have stressed the importance of understanding the perspectives of the participants in studying the teaching-learning context (Bussi, Chittenden, \& Amarel, 1976; Fenstermacher, 1979; Staton-Spicer, 1982; Wilson,1977). Erickson (1986), however, is among the most recent to suggest the importance of the local meanings that happenings have for the people involved in them: "In different classrooms, schools, and communities, events that seem ostensibly the same may have distinctly differing local meanings" (Erickson, 1986, p. 122). Cooper (1981) suggests the importance of a qualitative approach in understanding the participants' perspectives:

A naturalistic research process which employs multiple methods and taps the conscious and tacit knowledge of the instructor, student, and researcher enables us to describe how the dynamics of the instructional process are produced and interpreted . . . . The more that is known about what behaviors mean, the closer we can come to behaving in ways to accomplish the results desired. (p. 36).

\section{Specific Case}

Finally, data produced by qualitative methods meet the fourth criterion by allowing the instructional improvement 
process to focus on specifics. As Erickson (1986) suggests:

Answering the question, "What is happening?" with a general answer often is not very useful. "The teacher (or student) in this classroom is (are) on task" often doesn't tell us the specific details that are needed in order to understand the points of view of the actors involved. (p. 121)

Fieldwork methods, however, have the potential for providing specific understanding "through documentation of concrete details of practice" (Erickson, 1986, p. 121).

Although collecting data to be used for improvement of instruction is difficult, we find that we can obtain the most complete understanding of the dynamics of a classroom if we can generate information that represents the complexity of the classroom, accounts for context variables, incorporates the perspectives of the participants, and represents specifics of the case. Qualitative methods have provided us with a way of generating such data.

\section{APPLYING QUALITATIVE METHODS TO A TYPICAL CASE}

One way of increasing understanding of the use of qualitative methods to generate useful data for instructional development is to discuss individual cases. The following case, then, is presented as a specific application of qualitative methods to gather information for instructor and course improvement.

\section{A Case Study}

This case study represents the application of qualitative research methods for a course which was viewed as a departmental problem. The contact was initiated by the department chair in a professional program. The required course, which met all day long, one day a week, contained both a lecture and a laboratory component. In the mornings the 50 students attended two-hour lectures delivered by the same professor for the entire term. The remaining seven hours of each day were spent in the laboratory where students worked individually under the supervision of one of seven lab instructors.

An initial interview with the department chair suggested that the primary concern was the amount of time it was taking students to complete projects in the laboratory portion of the 
class. The chair reported that the instructors suspected that students were having difficulty transferring their learning from the lecture to the laboratory. Consequently, he was interested in specific instructional strategies which would assist students in applying the lecture material in the laboratory. He perceived, however, that students procrastinated, failed to use the laboratory manual, and expected to finish projects outside regularly scheduled laboratory time. As a result, they were not taking advantage of the supervision available during regularly scheduled laboratory hours. In addition, he felt that the existence of an "attitude problem" might be affecting students' ability to finish projects on time. He was interested in a student input that would assist instructors in improving the course and eliminating the problems.

Because of the need for an open-ended approach that provided detailed description of what was happening in the course, it was decided to use the qualitative methods of observation and interview to obtain data for the case. The interview data were obtained from the department chair and the students. The observational data were compiled by the consultants who worked on the project. The primary sources of data for this case, then, were the department chair, the observers and the students.

The chair provided qualitative input in two ways. First, he provided information in the initial interview with the consultants. At that time he discussed his concerns about the course and his perceptions of the reasons for the course difficulties. After the initial interview, he was asked to write responses to open-ended questions about goals of the course, instructors' expectations, and the relationship between the lecture and laboratory components of the course. From these data bases, it was determined that the variables of major concern to the director were related to use of laboratory time, completion deadlines, the link between the lecture and the laboratory, use of instructors' expertise during laboratory time, instructional strategies to increase student efficiency, and student attitudes.

Two consultants observed in the lecture and laboratory components of the course to develop perspectives on the most important instructional variables to be considered. The observers attended both the lecture and the laboratory sections of the course for ten collective hours. They used the variables identified 
by the director as a framework to sensitize them to possible areas of difficulty. However, they remained open to the emergence of variables that had not been previously identified by the department chair. From the observational data, the major instructional variable that needed to be addressed was related to expectations for the course. Analysis of observational data suggested that it would be important to clarify expectations about the course and the roles of the lecture, the laboratory, the instructors, and the students in meeting those expectations. These major areas of need, then, were used to develop the schedule of questions for interviews with the students.

Interviews with students provided the third, and primary, source of information for assessing the course. Using questions that focused students on expectations for the course and ways to meet those expectations, the consultants conducted one-toone interviews with 37 of the students in the class $(74 \%$ of the population). Each interview lasted 15-20 minutes. These interviews then provided not only major areas of student concern but also specific suggestions about how the course might be improved. Major areas of concern identified by the students were related to the link between lecture and laboratory, evaluation procedures in lecture and laboratory, amount of time spent working outside the laboratory, instructional strategies in the laboratory, and class atmosphere and reinforcement. The interview data provided detailed descriptions and quotations with which to clarify students' perceptions and make specific recommendations for improving the course.

The data generated for improvement of this course met the four criteria previously identified. The variety of interview and observation methods made it possible to obtain a more complete understanding of the complexity of the course. For instance, as data for the case were analyzed, it became evident that the problem involved more than transferring learning from lecture to laboratory. It was not only a matter of the way the students interacted with the content of the course but also a matter of the way that students and instructors interacted with each other over the content of the course. Consequently, such variables as the roles of instructors in the laboratory, standards of excellence, and methods of evaluation emerged. The exploratory approach characteristic of qualitative methods allowed for the emergence of these additional variables. 
Observation in the classroom and the laboratory provided opportunities to investigate contextual variables in the course. Data from the laboratory context, for instance, suggested that there were alternative instructor roles that could be incorporated to help students avoid time-consuming mistakes that they were making while they waited for assistance and feedback. In some cases the laboratory context prevented instructors from providing assistance at crucial times during the decision-making process. One instructor managed to adapt, however, by viewing his role as a demonstrator as well as an evaluator of student efforts. Working with his students as a group before they began to work individually, this instructor demonstrated how to anticipate and avoid time-consuming mistakes. As a result, he saved time for the students and himself. Studying the instructor in situ increased the investigators' understanding of the ways the demonstrative approach could be used in this course to assist students in completing projects on time.

The use of the perspectives of the participants also allowed the investigators to reach some important conclusions about the course. The opportunity to compare information across data sources, for example, allowed the researchers to determine that there were inconsistencies in the students' and instructors' perceptions of the course. Whereas the instructors thought that students expected to finish projects outside regularly scheduled laboratory time, students perceived that instructors expected them to spend additional time working independently on the projects. In this instance, understanding the perspectives of the participants allowed the investigators to identify inconsistencies of which neither the students nor the instructors were aware.

Finally, with the level of detail provided by the variety of qualitative methods, it was possible to focus more fully on the specific case. It was helpful to know not only that students were confused about applying concepts from the lecture in the laboratory but also that the confusion often stemmed from inconsistency in the way terminology was used by the instructor in the class. It was also helpful to know not only that instructors were setting up expectations for students to complete projects outside scheduled laboratory time but also that specific instructor behaviors were conveying those expectations to the students. Data that met the four criteria, then, provided a more complete understanding of the problems of the case. 
Once data were generated and analyzed, it was possible to process the information to determine the most significant variables to be considered in setting goals for improvement. The qualitative methods of obtaining and analyzing the data allowed the consultants to identify not only major areas of change for the course but also specific ways in which those changes might be implemented. In this case the use of qualitative methods to generate data for course improvement resulted in a set of recommendations which were quickly adopted and implemented by the department.

\section{SUMMARY}

The basic contention of this paper is that data collected to assist instructors in improving their teaching effectiveness are more useful when they meet certain criteria and that qualitative research methods provide ways of generating such data. Ideally, all instructors would be willing to spend enough time on their teaching to use a variety of qualitative methods in their efforts. Such efforts, then, could incorporate observation in the natural environment, videotape, interviews, and study of documents as qualitative methods useful for collecting data to improve teaching. Ongoing teacher improvement efforts using this greater variety of strategies would be taking advantage of the full potential of qualitative methods.

Realistically, however, many instructors are limited by the amount of time they can and will contribute to improve teaching efforts. The specific application in this paper is an example of what can be accomplished by adapting qualitative methods to meet the needs of busy instructors. The information collected met the four criteria for useful data. The data represented the complexity of the classroom environment, included context variables, incorporated the perspectives of the participants, and described the specific case. Qualitative methods provided a way of collecting information that could be analyzed, interpreted and translated into recommendations and changes. It is hoped that faculty development consultants can use ideas from this paper as an impetus to think creatively about the variety of ways that qualitative methodology can be employed to generate data useful for improving teaching effectiveness. 


\section{REFERENCES}

Bussi, A., Chittenden, E.A., \& Amarel, M. (1976). Beyond surface curriculum: An interview study of teachers' understandings. Boulder, CO: Westview Press.

Cooper, C.R. (1981). Different ways of being a teacher: An ethnographic study of a college instructor's academic and social roles in the classroom. Journal of Classroom Interaction, 16, 27-37.

Cooper, C.R. (1982). Getting inside the instructional process. Journal of Instructional Development, 5, 2-10.

Erickson, F. (1986). Qualitative methods in research on teaching. In M.C. Wittrock (Ed.), Handbook of research on teaching (Third ed.). New York: MacMillian Publishing Company, 119-161.

Fenstermacher, G.D. (1979). A philosophical consideration of recent research on teacher effectiveness. In L.S. Shulman (Ed.), Review of research in education 6. Itasca, IL: Peacock, 157-185.

Goetz, J.P., \& LeCompte, M.D. (1984). Ethnography and qualitative design in educational research. Orlando: Academic Press, Inc.

Lincoln, Y.S., \& Guba, E.G. (1985). Naturalistic inquiry. Beverly Hills, CA: Sage Publications.

McKenna, B.H. (1981). Context/environment effects in teacher evaluation. In J. Millman (Ed.), Handbook of teacher evaluation. Beverly Hills, CA: Sage Publications.

Miles, M.B., \& Huberman, A.M. (1984). Qualitative data analysis: A sourcebook of new methods. Beverly Hills, CA: Sage Publications.

Patton, M.Q. (1980). Qualitative evaluation methods. Beverly Hills, CA: Sage Publications.

Pedersen, K.G. (1975). Improving teacher effectiveness. Education Canada, 15, 13-20.

Philipsen, G. (1982). The qualitative case study as a strategy in communication inquiry. The Communicator, 12, 4-17.

Staton-Spicer, A.Q. (1982). Qualitative inquiry in instructional communication: Applications and directions. The Communicator, 12, 35-46.

Wilson, S. (1977). The use of ethnographic techniques in educational research. Review of Educational Research, 47, 245-265.

\section{NOTES}

1. For a thorough and relatively straightforward description of "how to" collect qualitative data in the various forms of interview, observation, and document study, see Goetz \& LeCompte (1984), Lincoln \& Guba (1985), or Patton (1980).

2. Researchers using qualitative methods need to become familiar with specific analy tic procedures including the use of conceptual frameworks and matrices. For discussion of qualitative data analysis, see Goetz \& Lecompte (1984); Miles and Huberman (1984); and Patton (1980). 